Gut, 1980, 21, 951-959

\title{
Studies on breath methane: the effect of ethnic origins and lactulose
}

\author{
PAULINE PITT, K M DE BRUIJN, MADELEINE F BEECHING, E GOLDBERG, \\ AND L M BLENDIS* \\ From the Department of Medicine, University of Toronto, Toronto General Hospital, Toronto, Canada
}

SUMMARY The prevalence of methane production in an adult population of 256 subjects was $41 \%$, but it was significantly higher in females $(49 \%)$, than males $(33 \%)$. When the population was subdivided into ethnic groups, Caucasians (48\%) and Blacks (45\%) had significantly more methane producers than Orientals $(24 \%)$ and Indians (32\%). When the ethnic groups were analysed by sex, female Caucasians had the highest prevalence $(58 \%)$, significantly more than Caucasian males, Oriental males, and females and Indian males. In contrast with previous studies, a single dose of lactulose was found to significantly increase breath methane concentrations in six out of 12 methane producers, but not in 25 non-methane producers from the population study. In conclusion, any studies on breath methane must take into consideration the ethnic origin of the subjects and, contrary to previous advice, substrate intake, especially undigestible carbohydrates. Furthermore, a single breath sample may miss up to one-fifth of methane producers.

A proportion of intestinal methane produced by anaerobic methanobacteria in the colon is excreted into the breath. ${ }^{1}$ In one series methane was found in the breath in only one-third of a population of 280 adults. ${ }^{1}$ There appeared to be a familial tendency and environmental factors were also thought to play a part. The ingestion of non-absorbable carbohydrates, such as lactulose and raffinose, ${ }^{12}$ appeared not to influence methane production. In this paper we report a study on the prevalence of methane production in a population consisting of four different ethnic groups, together with the acute effect of a single dose of the non-absorbable disaccharide, lactulose, on methane production.

\section{Methods}

\section{SUBJECTS}

The pulmonary excretion of methane was studied in a population of 256 healthy volunteers from the staff of two hospitals. The subjects were enrolled by two of us (PP, MFB) touring wards and laboratories asking for volunteers. One hundred and eighteen

\footnotetext{
*Address for reprint requests: Dr L M Blendis, 9th Floor, Eaton Wing, Toronto General Hospital, 585 University Avenue, Toronto, Ontario, M5G 1L7, Canada.

Received for publication 29 July 1980
}

were male and 138 female, with ages ranging from 19 to 59 years with an average of 34 years. None of these subjects was taking antibiotics or laxatives for at least seven days before the sampling. The group was investigated as a whole and then divided into subgroups according to their ethnic origin. This was established by the ethnic characteristics of their appearance and their place of birth. Only three of the 256 subjects (Indians) were related. Duplicate endexpiratory breath samples were collected via a modified Haldane-Priestly tube into $20 \mathrm{ml}$ plastic syringes attached to the side arm of the tube by a three-way stopcock. ${ }^{3}$ The methane content of both syringes was measured by gas chromatography, using a Carle AGC-311 equipped with a hydrogen flame detector. Breath components were separated at room temperature on a $2 \mathrm{~m} \times 6 \cdot 10^{-3} \mathrm{~m}$ (length $\times$ inner diameter) column, packed with molecular sieve $5 \AA$ ( $60-80 \mathrm{mesh})$. Nitrogen acted as carrier gas at a flow rate of $10^{-4} \mathrm{~m}^{3} / \mathrm{min}$. The value of breath methane production was calculated by comparison with a known standard and by subtracting the methane of room air from the average level of the duplicate samples. Subjects whose corrected values were less than $0.05 \mu \mathrm{mol} / 1 \quad(=1 \mathrm{ppm})$ were considered to be non-producers.

To determine the value of a single random breath sample in detecting the ability of an indi- 
vidual to produce methane, seven known methane producers, five female (four Caucasian and one Indian) and two Caucasian males, selected for their accessibility, were sampled for between eight and 48 days. In five subjects 14 of these days were consecutive.

The effect of a single dose of $20 \mathrm{~g}$ lactulose on methane production was studied in 12 methane producers who were readily accessible for the test. All 12, after a fasting breath sample had been taken as described previously, ingested $20 \mathrm{~g}$ lactulose in $30 \mathrm{ml}$ syrup and washed this down with a tumbler of water. Additional breath samples were then taken at 15 minute intervals for two to three hours. Twenty-five fasting subjects who did not produce methane on routine screening were also given $20 \mathrm{~g}$ lactulose in $30 \mathrm{ml}$ syrup washed down with a tumbler of water. Then breath samples were taken over a three hour period as described above.

STATISTICAL ANALYSIS

A first analysis of the data consisted of comparing the subgroups with the total population by the $\chi^{2}$-test for a $2 \chi$ K-table. ${ }^{4}$ Subsequently, individual groups were compared with each other by applying the fourfold contingency table. ${ }^{4}$ Changes in methane levels after the lactulose ingestion in the 12 producers were analysed with the paired Student's $t$ test. Differences were considered to be significant at the $\mathbf{P}<0.05$ level.

\section{Results}

The reproducibility of the duplicate sampling was assessed by comparing the first and the second breath samples. The difference was analysed using the paired $t$ test, which showed no significant difference. Therefore all results are reported as the mean of the two duplicate samples.

The results of long-term random sampling from individual methane producers are shown in Table 1. As the number of days sampled varied considerably from subject to subject, the results are expressed as number of producing days out of 10 . When calculated in this way the overall average daily detection rate for the seven subjects was $82 \%$, although this ranged from $100 \%$ down to $46 \%$-that is, in subjects who were positive $100 \%$ of the time, a single sample would be sufficient to detect methane production, while in the worst case, $46 \%$ positivity, at least six samples would be required to exclude methane production positivity. Consecutive sampling in five individuals for 14 days did not reveal any pattern of methane production. However, the number of positive days tended to correlate with the average breath methane concentration on those positive days $(r=0.63, \mathrm{P}=0.09)$, but not with the peak methane level.

In the population study 106 of the 256 subjects, or $41 \%$, were methane producers. However, the prevalence of methane production in females, 67 out of 138 , or $49 \%$, was significantly greater than in males, 39 out of 118 , or $33 \%(P=0.025)$. Dividing the population into four ethnic groups, Caucasian, Black, Oriental, and those originating from the subcontinent of India, gave methane production rates of $48 \%, 45 \%, 24 \%$, and $32 \%$ respectively (Table 2 ). The Caucasian females had significantly higher methane production rates than Caucasian males and both Oriental males and females $(\mathrm{P}<0.025)$ as well as Indian males $(P<0 \cdot 05)$. These differences were not related to age, as the ages in all groups were similar. Furthermore, these differences could not be explained by the large number of subjects who were borderline positive-that is, 0.05 to $0.09 \mu \mathrm{mol} / 1$ as opposed to negative. If anything, the difference between Caucasian males and females would be increased if the lower limit of positivity had been raised to more than $0.09 \mu \mathrm{mol} / \mathrm{l}$ (Table 2). Twenty-seven of the subjects were cigarette smokers and had smoked on the day of the breath sample. Only 10 , or $37 \%$, of these were methane producers, a figure which was not different from the overall percentage. Furthermore, eight

Table 1 Repeated single sampling in seven methane producers

\begin{tabular}{|c|c|c|c|c|c|}
\hline \multirow[t]{2}{*}{ Subject no. } & \multicolumn{2}{|c|}{ Number of days } & \multirow{2}{*}{$\begin{array}{l}\text { No. days possible } \\
\text { out of } 10\end{array}$} & \multicolumn{2}{|c|}{ Methane (umol/l) } \\
\hline & Measured & Producing & & Peak & Average \\
\hline $\begin{array}{l}1 * \\
2 \\
3 * \\
4 * \\
5 * \\
6 \\
7 * \\
\text { Total }\end{array}$ & $\begin{array}{c}19 \\
8 \\
16 \\
28 \\
23 \\
8 \\
48 \\
150\end{array}$ & $\begin{array}{r}19 \\
8 \\
16 \\
25 \\
17 \\
5 \\
22 \\
112\end{array}$ & $\begin{array}{c}10 \\
10 \\
10 \\
8 \cdot 9 \\
7 \cdot 4 \\
6 \cdot 3 \\
4 \cdot 6 \\
8 \cdot 2\end{array}$ & $\begin{array}{l}1 \cdot 20 \\
0.76 \\
0.54 \\
2 \cdot 36 \\
0.76 \\
0.31 \\
0.54\end{array}$ & $\begin{array}{l}0.61 \\
0.53 \\
0.23 \\
0.71 \\
0.26 \\
0.21 \\
0.19\end{array}$ \\
\hline
\end{tabular}

In five subjects, marked *, this sampling included a period of 14 consecutive days. The correlation between the number of days producing out of 10 versus the average breath methane concentration of the positive days is $r=0.626(P=0.09)$. 
Table 2 Prevalence of methane production in population of Caucasians, Blacks, Orientals, and Indians, according to sex

\begin{tabular}{|c|c|c|c|c|c|c|c|c|}
\hline \multirow[t]{2}{*}{ Ethnic group } & \multirow{2}{*}{ Sex } & \multirow{2}{*}{$\begin{array}{l}\text { Age } \\
\text { average (yr) }\end{array}$} & \multirow{2}{*}{$\begin{array}{l}\text { Total in } \\
\text { group (no.) }\end{array}$} & \multirow{2}{*}{ Total number } & \multicolumn{2}{|c|}{ Methane production } & \multicolumn{2}{|c|}{$\%$ Producing methane } \\
\hline & & & & & $\begin{array}{l}<0.09 \mathrm{\mu mol} / \mathrm{l} \\
(1-2 \mathrm{ppm})\end{array}$ & $\begin{array}{l}\text { Average } \\
(\mu \mathrm{mol} / \mathrm{l})\end{array}$ & By sex & Whole group \\
\hline \multirow[t]{2}{*}{ Black } & $\mathbf{M}$ & $35 \cdot 0$ & 29 & 12 & 1 & $\cdot 32$ & 41 & \\
\hline & $\mathbf{F}$ & $34 \cdot 0$ & 40 & 19 & 0 & $\cdot 31$ & 47 & 45 \\
\hline \multirow[t]{2}{*}{ Oriental } & $\mathbf{M}$ & $30 \cdot 7$ & 23 & 6 & 2 & $\cdot 24$ & 26 & \\
\hline & $\mathbf{F}$ & $32 \cdot 7$ & 23 & 5 & 0 & $\cdot 58$ & 22 & 24 \\
\hline Caucasian & $\mathbf{F}$ & $29 \cdot 4$ & 65 & 38 & 1 & $\cdot 84$ & 58 & 48 \\
\hline \multirow[t]{2}{*}{ Indian } & $\mathbf{M}$ & $34 \cdot 8$ & 15 & 3 & 0 & .91 & 20 & \\
\hline & $\mathbf{F}$ & $35 \cdot 8$ & 10 & 5 & 1 & .98 & 50 & 32 \\
\hline \multirow[t]{2}{*}{ All groups } & $\mathbf{M}$ & & 118 & 39 & 8 & & 33 & \\
\hline & $\mathbf{F}$ & & 138 & 67 & 2 & & 49 & 41 \\
\hline
\end{tabular}

subjects had smoked within 10 minutes of the test and only two were positive. No other significant differences were found between any of the other subgroups.

In the 12 methane producers who ingested lactulose the mean breath methane level went up

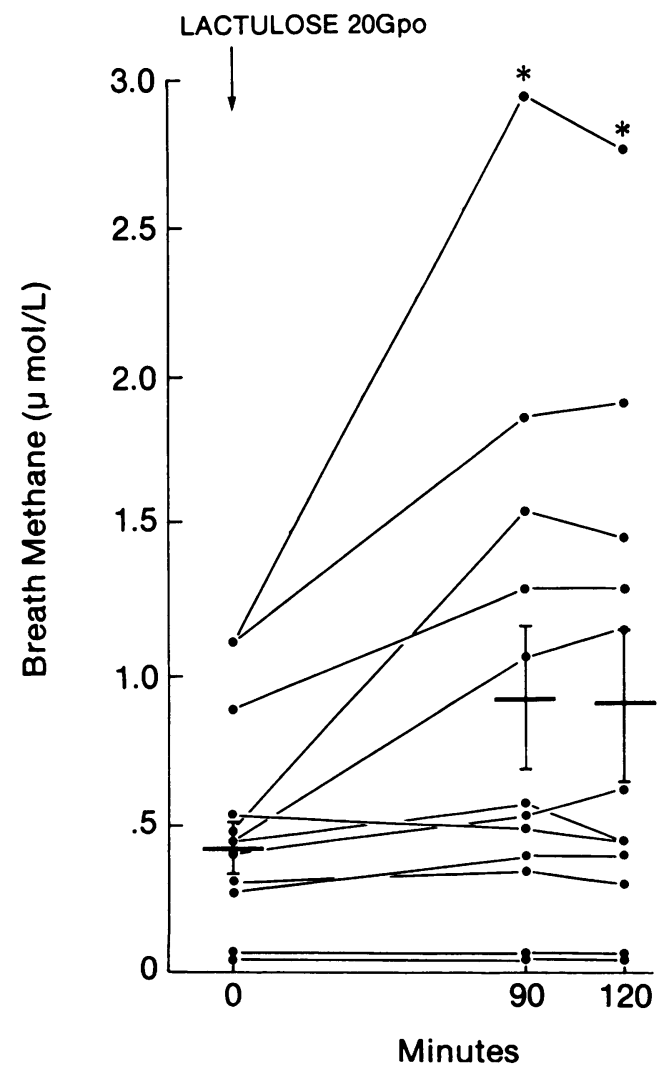

Figure Breath methane $(N=12)$ after a single dose of $20 \mathrm{~g}$ lactulose in 12 methane producers. Changes from the baseline were analysed with the paired Student's t test. ${ }^{*} \mathrm{P}=0.025$. from a baseline of $0.42 \pm 0.10 \mu \mathrm{mol} / 1$ to $0.94 \pm 0.25$ $\mu \mathrm{mol} / 1$ after 90 minutes $(\mathrm{P}=0.025)$ and to $0.91 \pm 0.24$ $\mu \mathrm{mol} / \mathrm{l}$ at 120 minutes $(\mathrm{P}=0.025)$ (Figure). Moreover, in this group only six showed a rise in the breath methane during the test, while the other six remained constant and at their baseline level. The rise was observed in those who had the highest baseline levels (Figure) $(r=0.89, P=0.00005)$. In contrast, none of the 25 non-methane producers excreted any methane after the lactulose ingestion, whereas 22 of them showed a significant rise in breath hydrogen level.

\section{Discussion}

We were interested to find differences in the overall incidence of methane producers of $41 \%$ compared with previous reports of $35 \%$, and $70 \%{ }^{5}$ A single sample of breath was used for this population study and it appears that other studies also used single samples, so increased frequency of sampling could not explain these differences. If the other studies measured breath methane more than once, this could explain some differences, as our data show that a single breath sample might miss an average of $18 \%$ of the methane producers in a population study. Another possible explanation is that in one study $^{5}$ it is not clear whether room air methane levels were subtracted as background. This, together with a difference in the cut-off point between producers and non-producers, might explain the difference between the two series, as in the present series there were 10 subjects whose breath methane concentrations fell between 0.05 and $0.09 \mu \mathrm{mol} / \mathrm{l}$ ( $<2$ ppm).

The population was then divided by sex and this showed a $33 \%$ male incidence which corresponded with previous findings, ${ }^{1}$ and a female incidence of $49 \%$. The increase in the incidence in females appeared to be due to Caucasian females who not only showed a significant increase in methane production compared with Caucasian males but also 
with Oriental females and males as well as Indian males.

In a breath methane study in familes, ${ }^{1}$ it was found on all seven occasions where both the offspring and only one parent were producing that the mother was the producer. This indicates a sexual difference that may have been overlooked.

In addition, we examined the sample of Caucasian women in our study and found that $39 \%$ of methane producers had been born in Europe, while only $14 \%$ of non-methane producers were European. When the subgroup of European-born Caucasian women was removed, no difference in the incidence of methane production in male and female Caucasians could be found. Furthermore, many of the Caucasian women had been in Canada for many years. Although genetic factors cannot explain the difference between Canadian and European born Caucasian females, environmental factors such as $\operatorname{diet}^{6}$ may play a part. Among Caucasian males, birthplace made no difference to methane status. Thus sex might be considered to play a modifying role in the influence of early environment on methane status.

In contrast with previous studies we have shown that lactulose ingestion can increase methane production. This should not be surprising, as hydrogen and carbon dioxide are end-products of bacterial metabolism of lactulose and may be substrates for methane production by methanogenic bacteria.? It is of interest, however, that half the subjects did not increase breath methane levels when given lactulose, despite rises in hydrogen production and the presence of baseline levels of methane. This indicates that available substrate does not ensure methane production in the presence of methanogenic bacteria.

Non-methane producers never had detectable breath methane after administration of $20 \mathrm{~g}$ lactulose; though most of them produced hydrogen. This was not surprising, as it would be unlikely that the acute administration of lactulose could alter the bacterial flora over such a short time. This study shows that many factors play a part in determining the ability of an individual to produce methane and the significance of this ability on the host has yet to be determined. For example, a previous study has shown an increased incidence of methane production in patients with carcinoma of the bowel. ${ }^{8}$ The mechanisms by which methane is produced appear to be multiple and may vary from one moment to another within the same individual, thus suggesting alterations in the metabolism of methanogenic bacteria within that individual or even alterations in the composition of the bacterial flora itself.

We would like to thank Miss Maxine Doody and Miss Barbara Kryla for assisting with the chromatographic studies and Miss Eileen Graham for typing the manuscript. Dr de Bruijn is sponsored by the Stichting Alcohol Fonds in the Hague, The Netherlands, and the Norman Urquhart Foundation of the Toronto General Hospital. We also thank Dr. Andres Lundell (Merrell Ltd, Canada) for supplying lactulose.

\section{References}

${ }^{1}$ Bond JH, Engel RR, Levitt MD. Factors influencing pulmonory methane excretion in man. J Exp Med 1971; 133: $572-88$.

${ }^{2}$ Tadesse K, Eastwood MA. Metabolism of dietary fibre components in man assessed by breath hydrogen and methane. Br J Nutr 1978; 40: 393-6.

${ }^{3}$ Metz G, Gassull MA, Leeds AR, Blendis LM, Jenkins DJA. A simple method of measuring breath hydrogen in carbohydrate malabsorption by end-expiratory sampling. Clin Sci Molec Med 1976; 50: 237-40.

${ }^{4}$ Rumke CL, Van Eeden C. Statistiek voor Medici Leiden: Stafleu en Zoon, 1961: 90-3 and 60-6.

${ }^{5}$ Calloway DH, Murphy EL. The use of expired air to measure intestinal gas production. Ann NY Acad Sci $1968 ; 150$ : 82-95.

${ }^{6}$ Steggerda FR. Gastrointestinal gas following food consumption. Ann NY Acad Sci 1968; 150: 57-66.

${ }^{2}$ Wolfe RS. Microbiol formation of methane. Adv Microbiol Physiol, 1971; 6: 107-46.

${ }^{8}$ Haines A, Metz G, Dilawari J, Blendis LM, Wiggins H. Breath-methane in patients with cancer of the large bowel. Lancet 1977; 2: 481-3. 